\title{
Recovery linked to life history of sessile epifauna following exclusion of towed-mobile fishing gear
}

Kaiser, Michel; Hormbrey, Samantha; Booth, Jonathan R; Hinz, Hilmar; Hiddink, Jan

\section{Journal of Applied Ecology}

DOI:

$10.1111 / 1365-2664.13087$

Published: 01/05/2018

Peer reviewed version

Cyswllt i'r cyhoeddiad / Link to publication

Dyfyniad o'r fersiwn a gyhoeddwyd / Citation for published version (APA):

Kaiser, M., Hormbrey, S., Booth, J. R., Hinz, H., \& Hiddink, J. (2018). Recovery linked to life history of sessile epifauna following exclusion of towed-mobile fishing gear. Journal of Applied Ecology, 55(3), 1060-1070. https://doi.org/10.1111/1365-2664.13087

\section{Hawliau Cyffredinol / General rights}

Copyright and moral rights for the publications made accessible in the public portal are retained by the authors and/or other copyright owners and it is a condition of accessing publications that users recognise and abide by the legal requirements associated with these rights.

- Users may download and print one copy of any publication from the public portal for the purpose of private study or research.

- You may not further distribute the material or use it for any profit-making activity or commercial gain

- You may freely distribute the URL identifying the publication in the public portal ?

Take down policy

If you believe that this document breaches copyright please contact us providing details, and we will remove access to the work immediately and investigate your claim. 


\section{Recovery linked to life-history of sessile epifauna following}

\section{3 exclusion of towed-mobile fishing gear}

4 Michel J. Kaiser, Samantha Hormbrey, Jonathan R. Booth, Hilmar Hinz ${ }^{1}$, \& Jan G. Hiddink

5 School of Ocean Sciences, Bangor University, Menai Bridge, Anglesey, LL59 5AB, UK

$6{ }^{1}$ Mediterranean Institute for Advanced Studies (UIB-CSIC), C/Miquel Marques, 21, Esporles 07190, Spain 7

$8 \quad$ Author for correspondence: michel.kaiser@bangor.ac.uk

\section{Abstract}

1. The use of reserves as conservation tools is wide-spread. However, evaluating the effectiveness of reserve implementation for long-lived species has been problematic as it requires sampling regimes on the long time-scales that are appropriate to species' longevity and recovery rates. In the sea, towed bottom-fishing gears alter the biodiversity and ecosystem services provided by benthic communities and habitats. Marine reserves have been used to manage these impacts but our understanding of the drivers of their effectiveness for the conservation of temperate reefs is incomplete.

2. We examined the effectiveness of marine reserves for recovery of temperate reef fauna in relation to their life-history. We used an underwater video to sample six species with different

20 life histories across 60 sites that varied in the duration of protection from towed mobile 21 fishing gear at $0,1,8$ and 10 years.

22 3. Species with a high dispersal potential and less habitat specific requirements such as soft

23 corals and king scallops recovered to close to their carrying capacity in $<3$ years. In contrast,

24 the longer-lived Ross coral and pink seafans increased in abundance but had not fully recovered and their projected recovery time was 17 to 20 years. 
26 4. Ongoing recovery was evident for long-lived species as their mean body-size increased

27 significantly across all treatments, whereas shorter-lived species such as queen scallops did

28 not change in size and were assumed to have fully recovered.

29 Applications and synthesis: The present study shows that the recovery rates of biota depend 30 on their life-history, such as larval longevity and dispersal potential. Recovery for species 31 that had low dispersal potential and specific habitat requirements was slow and could take $32>20$ years. This suggests that activities such as bottom-trawling or dredging should be 33 avoided where such species occur if their conservation is an objective. In contrast, species 34 with high dispersal potential and less habitat specific requirements had shorter recovery 35 timescales of $\sim 2-3$ years and would be more amenable to managed trawl frequencies in 36 areas where activities such as fishing occur.

37 Key words: scallop dredging, Eunicella verrucosa, pink seafans, Alcyonium digitatum, 38 Pentapora fascialis, Phallusia mammillata, marine protected areas, towed mobile fishing 39 gears, biogenic reefs

$40 \quad$ Word count : 6921 


\section{INTRODUCTION}

Marine protected areas or reserves are one of the many management tools that can contribute to the ecosystem-based approach to fisheries management (Jennings and Kaiser, 1998; Roberts et al., 2005), which seeks to promote the sustainable use of marine resources whilst maintaining biodiversity and protecting habitats (Worm et al., 2006). Marine protected areas (MPAs) can provide partial or total protection from fishing activities and can have positive outcomes within the boundaries of MPAs (Auster and Shackell, 2000; Blyth-Skyrme et al., 2006; Sciberras et al. 2015).

MPAs are of particular value as conservation tools when they are used to limit (or remove) activities that directly threaten particular seabed habitats or sessile species associated with those habitats (Hinz et al., 2011; Sheehan et al., 2013a,b). The implementation and design of effective MPAs requires a multi-disciplinary approach, together with an understanding of the ecological and life-history traits of the protected species, physical environment and natural disturbance regime (Claudet et al., 2010, Stewart et al., 2009; Sciberras et al., 2013). Many marine species are highly mobile and migratory (Willis et al., 2003), ranging over vast areas that exceed the boundaries of an MPA, potentially reducing their effectiveness.

\section{EFFECTS OF SCALLOP DREDGING ON SEABED BIOTA}

In Europe, scallop fisheries have increased considerably over that last ten years and were ranked as the third most valuable fishery in the UK in 2014 (MMO 2014). Although they are economically valuable, scallop dredge fisheries have well-known adverse effects on benthic communities, leading to reductions in diversity and production (Kaiser et al., 2002; Lambert et al. 2015). Nevertheless, the effects of scallop dredging vary considerably according to the environmental context in which scallop dredging occurs, such that some benthic communities exhibit higher resilience to disturbance than others (Hiddink et al., 2017). Of particular concern are the effects of dredges (and other towed mobile fishing gears) on 
stable biogenic habitats, such as reefs, or on longer-lived fauna. The species that create biogenic habitats, such as corals, often form complex ecological associations and tend to be long-lived, slow growing and fragile, sensitive to disturbance, and vulnerable to damage (Hinz et al., 2011; Coma et al., 2004; Garcia et al., 2006). Despite their ecological importance, our understanding of the recovery potential of biogenic habitats following disturbance by towed bottom fishing gears has been restricted by the limited opportunities to study recovery dynamics in such environments, and more importantly the long time-scales over which such studies need to be carried out to allow detecting recovery (Hall-Spencer and Moore, 2000; Hinz et al., 2011; Williams et al., 2010; Cook et al., 2013; Boulcott et al., 2014). Estimates either suggest that no recovery occurs within the timescale of the study (e.g. Hall-Spencer and Moore, 2000 [4 years] and Cook et al., 2013 [5 years]) or suggest that some biogenic habitats (particularly sponges and soft corals) could require up to, or more than, 20-30 years before signs of recolonization and recovery may occur (Sainsbury 1998; Williams et al., 2010).

Evaluating the effectiveness of reserve implementation for long-lived species has been problematic as it requires sampling regimes over the long time-scales that are appropriate to their longevity and recovery rates. Here, we examine the link between the life-history of species and reserve effectiveness. The present study reports the changes that have occurred over 10 years in a MPA [Lyme Bay special area of conservation (SAC) (U.K.)] by comparing the abundance and size of benthic fauna at varying periods after closure to towed mobile fishing gear. It is important to note that the SAC has remained open to fishing with static fishing gear that have little physical impact on the seabed (Coleman et al., 2013). We anticipated that species that have fast growth rates and high dispersal potential would have achieved their maximum abundance and size in the 10 years since closure (king and queen scallops, dead men's fingers), whereas slower growing species or those with limited dispersal capability may not have recovered fully to their unimpacted status (Ross coral, pink seafans, white sea squirts). 


\section{METHODS}

\section{STUDY CONTEXT}

In 2007 , to investigate the effects of protection and fishing activity on epifaunal community composition, a survey conducted by Hinz et al. (2011) assessed differences in the size and abundance of nine species under different levels of protection and previous fishing activity. The same nine species were studied herein (Hinz et al., 2011) with a view to recording changes in the size and abundance of these species with time (Figure 1). The species included; the nationally protected pink sea fan Eunicella verrucosa (Pallas, 1766), branched sponge Axinella dissimilis (Bowerbank), dead men's fingers Alcyonium digitatum (L.), Ross corals Pentapora foliacea (Ellis \& Solander, 1786) and white sea squirts Phallusia mammillata (Cuvier, 1815). Four commercially important species were also quantified; king scallop Pecten maximus, queen scallop Aequipecten opercularis, brown crab Cancer pagurus (L.) and spider crab Maja squinado (Herbst).

\section{EXPERIMENTAL DESIGN}

The experimental design was implemented across the four voluntary reserves that were established in 2006. The first factor examined was fishing-history and the protection status in 2006 (hereafter termed fishing history) with four different levels: closed not-fished (CNF), within the voluntary reserve boundaries and not previously scallop-dredged; closed fished (CF), within the voluntary reserve boundaries but scallop-dredged previously; open notfished (ONF), outside of the voluntary reserve boundaries but not previously scallopdredged; and open fished (OF), outside of the voluntary reserve boundaries and previously scallop-dredged. The second factor was year with two different levels: 2007 and 2016. In the original study we undertook two separate surveys in 2007 , these have been combined and values averaged. Data for the East Tennents reserve was eventually eliminated from the 
analysis due to the poor quality of the video footage obtained and the lack of sufficient replication.

For the 2007 surveys, previous fishing effort was determined using high-resolution track plots continuously recorded from fishermen's chart plotter data conducted between 2000 and 2006 (Hinz et al., 2011). This information was voluntarily provided by fishermen from five scallop dredge boats in the area, accounting for approximately $12 \%$ of the local fleet, and was considered representative of effort distribution by the South West Inshore Fishermen's Association (SWIFA). Fishing effort was calculated in ArcGIS 9.2 (ESRI) as the number of times a 500 x 500 m area was dredged between 2000 and 2006 (Hinz et al., 2011). Local fisheries by-laws meant that all vessels fishing within 6 nautical miles of the shore were under $12 \mathrm{~m}$ in length and were restricted to fishing with a total of 12 dredges (V Gravestock, Southern Inshore Fisheries and Conservation Association, pers. comm.). The data significantly correlated with fisheries patrol aircraft sightings of the whole fleet during the same time-period and so was considered the most accurate data source for describing the general fishing effort and spatial coverage within Lyme Bay prior to implementation of the MPA (Hinz et al., 2011). Five replicate sample sites were selected at random for each of the remaining treatment combinations in each reserve (Figure 1) (Hinz et al., 2011). Sixty-six of the sites sampled in 2007 were re-sampled in 2016, of which 60 were considered valid for the temporal comparisons with the baseline survey.

\section{VIDEO SAMPLING}

In 2007 epifaunal communities were sampled using a towed high definition digital camera system on a towed sled with parallel laser points for scale reference measuring only those animals that occurred at a consistent point in the field of view of the digital image (see Hinz et al. 2011). In 2016 epifaunal communities were sampled using video footage taken from a towed flying array (Sheehan et al., 2010). A silver Hero 4 GoPro camera, was used to record high definition video footage of the benthos, and three XTAR D26 LED dive torches (1000 lumen), were attached to the array and were all positioned at a $45^{\circ}$ angle to the seabed 
(Stevens et al., 2014), congruent with the angle used in the baseline survey (Hinz et al., 2011). Two green lasers mounted in parallel projected parallel dots $17.5 \mathrm{~cm}$ apart to provide a constant reference for size measurements (Stevens et al., 2014). The GoPro video cameras were set to a standard resolution of $720 p, 30$ frames per second to reduce blurring and a narrow field of view to reduce image distortion.

At each sample site the array was towed for approximately 10 minutes at a speed of $\sim 0.5$ knots $\left(0.25 \mathrm{~ms}^{-1}\right)$. GPS positions were recorded using a handheld Garmin eTrex 10 plotter, at the point when the array reached the seafloor and at the point when it was lifted clear from the seabed and were used to calculate the distance travelled by the array for each tow using the GPS positions (see www.datadryad.org). Video tows were positioned as close as possible to the corresponding location sampled in the baseline survey (Figure 1). From the digital images the following data were extracted: abundance and body or colony-size of the epifaunal species listed in the introduction, a visual classification of the surficial seabed sediment habitat (see S1 for methods).

Given that we used different vessels and camera systems for the 2007 and 2016 surveys there is the potential to introduce survey artefacts which may have influenced the results. We consider that the survey vessel effect is irrelevant in this instance as the video material provides a direct measure of sample quality. In addition, the effect of a changing field of view was an issue in both surveys (due to wave action), however this effect could be accounted for by the use of parallel laser pointers which provided a constant reference point in both surveys. If a scaling error was present, this would be presented as a consistent affect across all species, however the results indicate that size of individuals or colonies was either consistent or increased, but not in a uniform fashion across the two surveys. For these reasons we consider that the data generated across the surveys is comparable. 
A full two-way factorial design with interaction terms was used to analyse the data. The two factor levels were fishing history and year (2007 vs 2016) (see Table 1). The data collected during the 2007 March and August surveys were pooled (and averaged) to increase the statistical power to detect temporal changes that occurred between 2007 and 2016. Samples obtained at East Tennents were removed from the statistical analyses due to a lack of replication for this site. All univariate analyses were performed using $R$ v.3.3.0.

The effect of previous fishing history and time on epifaunal species abundance and size was analysed in R using General Linear Models (GLMs) with a Gaussian distribution (Zuur et al., 2009). Model assumptions were checked visually in $R$ and transformations were applied to the data when appropriate. If the data did not conform to a Gaussian distribution, then log transformations were applied $(\log (n+1))$. We raised the level at which we accepted a significant effect had occurred to $\alpha=0.1$ to reduce the risk of Type II errors. We did this because the species studied are protected by legislation and hence it was important to be precautionary in the interpretation of our data. A Tukey LSD post-hoc test was used to determine pair-wise difference when treatment effects were detected, again with $\alpha=0.1$ (see Thrush et al., 1995 for a justification of taking this precautionary approach).

Given the time-line of the implementation of the various area closures we were able to explore the potential recovery rate of the individual species using the following method. We treated the areas that had never been fished (the ONF and CNF sites) as an indicator of the carrying capacity $K$ of the system for each species. We calculated the mean abundance for each species for each of these treatments (calculated from the mean of each of the replicate locations for each treatment) in both 2007 and 2016. This provided us with four measures of $K$. We then calculated the mean value of $K$ and used this as a reference point that would indicate full recovery. For the areas that were exposed previously to fishing, our sampling regime provided estimates of abundance at year $0,1,8$ and 10 years post fishing (for explanation see Table 1). By calculating the mean of the mean abundance at each replicate site per treatment we have only one data point per time period, however, given that we have 
some replication with time we consider that precision of the estimate at each time point is of greater value for the calculation of recovery. Given the low level of replication using this approach, we treat this analysis with caution. Logistic curves of the change in abundance vs. time were fitted and the time to $80 \%$ and $95 \%$ recovery of mean $K$ was estimated (hereafter t80 and t95) using the non-linear regression (Abundance $\sim B_{t}{ }^{*} K /\left(B_{t}+\left(K-B_{t}\right){ }^{*} \exp \left(-r{ }^{*} t\right)\right.$ ), where $\mathrm{B}_{\mathrm{t}}$ is the abundance at time $t=$ years of protection and $\mathrm{K}$ was estimated as specified above). This analysis was not attempted for $C$. pagurus or $M$. squinado as these are mobile species and continued to be fished by static gear fisheries.

Size measurements could not be obtained from all of the individual organisms or colonies (note pink seafans, dead men's fingers, and Ross corals form colonies) observed in the video footage. To calculate the mean size of a particular species at a given site, only sites with three or more size measurements contributed to the calculation of mean size. Four species: dead men's fingers, pink sea fans, queen and king scallops, met these quality assurance criteria. While there were an insufficient number of replicates for a temporal analysis of possible change in mean size of Ross coral and white sea squirts, there were a sufficient number of replicates to make comparisons between the four fishing history treatments using only the 2016 data. The effect of previous fishing history and time on the size of each of these species was analysed as outlined above. We undertook a more indepth examination of size-frequency distributions of pink sea fans for 2007 and 2016 across the four fishing treatments. Pearson's chi-squared tests were used to test for differences in the frequency distributions $(\alpha=0.1)$. 


\section{RESULTS}

\section{VARIATION IN SUBSTRATUM TYPE}

Univariate analysis showed that the percentage cover of gravel recorded in the surveys in 2016 was marginally higher than in 2007 (increase from c 5\% to 10\%) (Mann Whitney U test, $W=1148, P<0.002)$ (Figure 2). The percentage cover of all other substratum types did not vary between years. Thus the habitats surveyed in 2007 and 2016 were highly consistent between surveys and did not introduce habitat confounding effects when considering any changes in species abundance, size and habitat association.

\section{SPECIES ABUNDANCE}

When we pooled the data from the two surveys undertaken in 2007 for the nine species of interest a total of 7,675 individuals were observed from $11,838 \mathrm{~m}^{2}$ of the seabed (65 indiv $100 \mathrm{~m}^{-2}$ ). In contrast, 12,757 individuals were observed from $11,969 \mathrm{~m}^{2}$ of the seabed in 2016 (107 indiv $100 \mathrm{~m}^{-2}$ ) which is a $65 \%$ increase in abundance.

Analyses of the change in the abundance of each of the nine species with time and among fishing-history treatments were not consistent among the species. Pink sea fans, Ross coral and branched sponges had identical responses such that there was no change in their abundance across the fishing-history treatments with time, whereas there was a significant effect of fishing-history with the highest abundance of individuals in the closed not-fished (CNF) sites (Figure 3, Table 2). In contrast, the two other sessile species, dead men's fingers and white sea squirts, had significant effects for both time and fishing-history treatments, with a significant interaction term for dead men's fingers. In both cases, there was a consistent increase in abundance across all fishing-history treatments. For the commercially important species, there was no significant effect of time or fishing-history treatment for king and queen scallops and brown crab but there was a significant decrease in the abundance of spider crab that varied with time and with fishing-history (Figure 3, Table 2). 


\section{SPECIES RECOVERY TRAJECTORIES}

Species recovery plots indicated that recovery to $80 \%$ of carrying capacity (t80) would take between 2.5 - 6 years for king scallops and dead men's fingers respectively (although neither of these fitted relationships was significant), whereas recovery to t80 was projected to occur from 17 - 20 years for Ross coral, white sea squirts and pink sea fans respectively (Figure 4). The maximum time to recovery to t95 was 51 years for yellow branched sponges. No recovery times were calculated for queen scallops as the abundance of this species was well above $\mathrm{K}$ in the previously fished stations at the start of the study and remained above $\mathrm{K}$ throughout.

\section{CHANGES IN SIZE}

The mean size of dead men's fingers increased from 2007 to 2016 in the OF, ONF and CF sites (4.3, 1.7 and 2.9 times greater in size, respectively, Figure 5, Table 2), however no significant difference was seen between years at CNF sites (Figure 5). Similarly, in 2016, pink sea fans were significantly larger than in 2007 at CNF and OF sites (2.4 and 3.1 times bigger, respectively) overall there was no difference in mean size between fishing-history treatments (Figure 5, Table 2 and S2). Analysis of the mean size of Ross corals and white sea squirts in 2016 showed no significant effect of fishing history on Ross coral size, however white sea squirts were larger in the ONF sites compared to the CNF sites (Figure 5, Table 2 and 3). King scallops increased in size across all fishing-history treatments from 2007 to 2016 in contrast to the size of the shorter-lived queen scallops which did not change in mean size with time (S2). The size frequency distributions of pink sea fans were significantly different between years at ONF, OF and CF sites $\left(X^{2}=40\right.$, d.f. $=18, P=0.04$; $X^{2}=40$, d.f. $=28, P=0.07 ; X^{2}=50$, d.f. $\left.=35, P=0.05\right)$, but not at CNF sites $\left(X^{2}=60\right.$, d.f. $=$ $54, P=0.27)$. At ONF and CF sites, a significant increase in the number of pink sea fan individuals in larger size classes was observed between 2007 and 2016 (Figure 6). 


\section{DISCUSSION}

The present study enabled us to investigate the temporal changes in the abundance and body-size distribution of temperate reef fauna with contrasting life-history strategies following the exclusion of towed bottom-fishing gears. Most importantly we have gained some insight into the recovery rate of long-lived species such as pink sea fans and Ross corals which have recovery times (to t80: $80 \%$ of carrying capacity) of between $17-20$ years. Shorterlived species such as scallops and dead men's fingers had much shorter recovery times of $2.5-6$ year. Although neither predictive relationship was significant in the formal analysis for the latter two species, these recovery times are similar to other studies (Sciberras et al. 2013; Lambert et al. 2015). We set out to be precautionary and avoid Type II errors by setting $\alpha=0.1$ as our level of significance (Thrush et al. 1995), but in the majority of cases the effects of fishing had probabilities $<<0.05$.

\section{EFFECTS OF THE CLOSURE ON SPECIES ABUNDANCE}

The effects reported herein share similarities with those reported elsewhere (Hall-spencer and Moore, 2000; Cook et al., 2013; Boulcott et al., 2014). Hinz et al. (2011) reported negative effects of fishing on the abundance of dead men's fingers, and Ross corals, and on and the presence of branching sponges in Lyme Bay in 2007, but no effect of fishing was observed for pink seafans. This finding found was contrary to expectation, and it was concluded that the impacts from gangs of scallop dredges was less severe within rocky habitats, perhaps due to the uneven topography of the seabed which may provide areas of protection or refuge from gears different gear (Hinz et al., 2011; Boulcott \& Howell 2011). This contrasts with the findings of the present study in which there was a positive effect of the MPA (Lyme Bay SAC) on the abundance and size of pink seafans that had been protected from towed mobile fishing gear for a much longer period of time. 
In the present study we found that despite increases in the average abundance of Ross coral across each fishing treatment since the Lyme Bay SAC was implemented, no significant effect of time on abundance was found. This differs to the findings of the short term studies, that were conducted 3 years following the establishment of the MPA (Sheehan et al., 2013a, b), which observed significant increases in abundance over time. Hinz et al., (2011) also observed an increase in Ross coral abundance over a period of 5 months following implementation of the four initial reserves in 2006, however this increase was perceived to reflect seasonal differences rather than a recovery response. Typically Ross coral are considered sensitive species (Milazzo et al., 2009) with a growth rate estimated at 2-3 cm per year. Ross coral have a lecithotrophic larval phase, lasting less that one day (Cocito, 1998), a life-history characteristic that limits dispersal and would favour habitat specialists (Lombardi et al., 2008; Hinz et al., 2011). Thus, it is perhaps not surprising that in the present study our projected recovery time to t80 was 16.6 years given the low rate of dispersal of larvae to areas around the adult population.

Eight years following the implementation of the MPA, white sea squirts were considerably more abundant than in 2007. White sea squirts appear to begin recovery within the first three years after the MPA was implemented (Hinz et al., 2011; Sheehan et al., 2013a, b). White sea squirts, similar to pink seafans and Ross coral, produce free swimming larvae that settle rapidly onto the seabed after a few days (Berrill, 1930). This short larval duration means that recruitment will be entirely reliant on local populations of adults (e.g. Lambert et al. 2015) and would explain why our predicted time to reach t80 was nearly 20 years (Figure 4).

In contrast to the species above, dead men's fingers have a higher recovery potential compared to other longer-lived sessile emergent species, due to their high fecundity and spawning strategies (Budd, 2008). Once fertilised, the lecithotrophic planulae can remain in the water column more than 10 days and can disperse more than $10 \mathrm{~km}$ (Hartnoll, 1974; 
Budd, 2008). Sheehan et al. (2013a) found an increase in the abundance of dead men's fingers within the MPA but not outside the MPA, 3 years after closures were implemented. In the present study, dead men's fingers increased across all fishing treatments and remained most abundant in the closed not-fished area (CNF). Our predicted time to t95 was 2.5 years which is similar to the recovery time-scales reported by Lambert et al. (2015) for the Isle of Man (c. 5 years).

\section{CHANGES IN SIZE OF INDIVIDUALS}

Dead men's fingers increased in size across all treatments except in the closed not-fished sites, which suggested that individuals within this area represent the upper-limit of body-size for this species in this locality. No differences in Ross coral size were found between the four fishing history treatments, suggesting that maximum size had been reached (Table 3). Pink seafans increased in size across all fishing-history treatments. The apparent increase in body size within the closed not fished (CNF) treatment may be attributed to a reduction in the frequency of interactions with static fishing gear (Eno et al., 2001). Anecdotal evidence from the local management agency (Inshore Fisheries and Conservation Association) suggests that whilst static gear effort within the MPA has not increased since the closures were implemented in 2008, static gear effort appears to have spread out over a wider area such that fishing intensity is lower (S. Pengelly, pers. comm., $14^{\text {th }}$ September 2016). Such a response would occur as the risk of negative interaction between the towed gear sector and static gear sector was removed (Blyth et al. 2002). Thus, a reduction in the intensity of fishing activities per se may have led to an increase in the body size distribution of individuals of some species such as pink sea fans.

\section{CHANGE IN ABUNDANCE AND SIZE OF TARGET SPECIES}

In contrast to expectations based on other studies (Beukers-Stewart et al. 2005; Sciberras et al., 2013), there was only a modest increase in the abundance of king scallops with time. However, our predicted recovery trajectory suggested that the scallop population may 
already be at carrying capacity in Lyme Bay. Sheehan et al. (2013) reported much higher abundances of king scallops in the areas of seabed they studied within Lyme Bay, which could suggest that the areas (type) of seabed surveyed in the present study may have been less suitable for king scallops, or these differences may relate to temporal and spatial variation in recruitment.

\section{CONCLUSIONS AND IMPLICATIONS FOR MANAGEMENT}

The implementation of reserves as conservation tools define spatial areas within which human activites can be managed. However, reserves are still subject to diffuse anthropogenic disturbances such as pollution and environmental changes such as warming sea temperatures. We cannot rule out the latter as potentially contributing to some of the effects we observed, such as some of the increases in organism size which could be related to temperature. Nevertheless, following the implementation of protection from fishing in Lyme Bay, the current study has provided evidence that over the last 10 years the change in status for most species was positive and had either reached or is moving towards carrying capacity. Increases in size for the longer-lived species indicated recovery towards an improved size-structure in these populations. The study highlights that differences in species life-history traits may be useful predictors of recovery rate. We found that all of the species with poor dispersal capability had slow predicted recovery rates, whereas species that had high larval dispersal (e.g. dead men's fingers and scallops) had relatively rapid recovery rates.

Any future consideration of towed mobile fishing activities within the boundaries of the current marine protected area should avoid entirely the rock reef and other areas of substantial hard substrata that have a strong affinity with species with poor dispersal capabilities (Hinz et al., 2011). Alleviation of the intensity of static gear fishing pressure may have contributed to some of the positive outcomes detected in this study (i.e. increasing body-size in pink sea fans) and would warrant further investigation. When the conservation of long-lived species is the objective of spatial management measures, our findings suggest 
that activities that lead to a reduction in species abundance such as trawling and dredging are incompatible within such areas. It may also be important to define the upper threshold of the intensity of other activities that may cause mortality of long-lived species (e.g. pot fishing), such that management measures (e.g. effort control) can be implemented that maintains the long-lived species in a favourable status. In contrast, some species such as dead men's fingers are more resilient to the effects of towed fishing gear given their shorter recovery timescale and low intensities of trawling may be sustainable for this species.

Author contributions: MJK, SH, JB collected and analysed the data, JGH analysed the recovery plots, MJK, JGH and $\mathrm{HH}$ conceived the original study. All authors wrote the paper.

Acknowledgements: The original study was funded by NERC NE/E011268/1, the current study was supported through the provision of a vessel for the survey work by Nick and Stacey Prust. The authors thank Captain Chris Acton for his assistance throughout the survey work. None of the authors has any conflict of interest related to this study.

\section{REFERENCES}

Auster, P.J. \& Shackell, N.L. (2000) Marine protected areas for the temperate and boreal Northwest Atlantic: the potential for sustainable fisheries and conservation of biodiversity. Northeastern Naturalist, 7, 419-434.

Berrill, N.J. (1930) Studies in tunicate development. Part I. General physiology of development of simple ascidians. Philosophical Transactions of the Royal Society of London B, 218, 37-78.

Beukers-Stewart, B.D., Vause, B.J., Mosley, M.W., Rossetti, H.L. \& Brand, A.R. (2005) Benefits of closed area protection for a population of scallops. Marine Ecology Progress Series, 298, 189-204. 
Blyth-skyrme, R.E., Kaiser, M.J., Hiddink, J.G., Edwards-jones, G. \& Hart, P.J. (2006) Conservation benefits of temperate marine protected areas: variation among fish species. Conservation Biology, 20, 811-820.

Boulcott, P., Millar, C.P. \& Fryer, R.J. (2014) Impact of scallop dredging on benthic epifauna in a mixed-substrate habitat. ICES Journal of Marine Science, 71, 834-844.

Boulcott, P. \& Howell, T.R., 2011. The impact of scallop dredging on rocky-reef substrata. Fisheries research, 110, 415-420.

Claudet, J., Osenberg, C.W., Domenici, P., Badalamenti, F., Milazzo, M., Falcón, J.M., Bertocci, I., Benedetti-Cecchi, L., García-Charton, J.A., Goñi, R. \& Borg, J.A. (2010) Marine reserves: fish life-history and ecological traits matter. Ecological applications, 20, 830-839.

Cocito, S., Sgorbini, S. \& Bianchi, C.N. (1998) Aspects of the biology of the bryozoan Pentapora fascialis in the north western Mediterranean. Marine Biology, 131, 73-82.

Coleman, R.A., Hoskin, M.G., Von Carlshausen, E. \& Davis, C.M. (2013) Using a no-take zone to assess the impacts of fishing: Sessile epifauna appear insensitive to environmental disturbances from commercial potting. Journal of Experimental Marine Biology and Ecology, 440, 100-107.

Coma, R., Pola, E., Ribes, M. \& Zabala, M. (2004) Long-term assessment of temperate octocoral mortality patterns, protected vs. unprotected areas. Ecological Applications, 14, 1466-1478.

Cook, R., Fariñas-Franco, J.M., Gell, F.R., Holt, R.H., Holt, T., Lindenbaum, C., Porter, J.S., Seed, R., Skates, L.R., Stringell, T.B. \& Sanderson, W.G. (2013) The substantial first impact of bottom fishing on rare biodiversity hotspots: a dilemma for evidence-based conservation. PloS one, 8, e69904. 
Defra. (2008) Explanatory memorandum to the Lyme Bay designated area (fishing restrictions) order 2008: 2008 No.1584. London: Defra.

Dinmore, T.A., Duplisea, D.E., Rackham, B.D., Maxwell, D.L. \& Jennings, S. (2003) Impact of a large-scale area closure on patterns of fishing disturbance and the consequences for benthic communities. ICES Journal of Marine Science, 60, 371-380.

Eno, N.C., MacDonald, D.S., Kinnear, J.A., Amos, S.C., Chapman, C.J., Clark, R.A., Bunker, F.S.P. \& Munro, C. (2001) Effects of crustacean traps on benthic fauna. ICES Journal of Marine Science, 58, 11-20.

Garcia, E.G., Ragnarsson, S.Á. \& Eiríksson, H. (2006) Effects of scallop dredging on macrobenthic communities in west Iceland. ICES Journal of Marine Science, , 63, 434443.

Hall-Spencer, J. M. \& Moore, P. G. (2000) Scallop dredging has profound, long-term impacts on maerl habitats. ICES Journal of Marine Science, 57, 1407-1415.

Hartnoll, R.G. (1975) The annual cycle of Alcyonium digitatum. Estuarine and Coastal Marine Science, 3, 71-78.

Hiddink, J.G., Jennings, S., Kaiser, M.J., Queirós, A.M., Duplisea, D.E. \& Piet, G.J. (2006) Cumulative impacts of seabed trawl disturbance on benthic biomass, production, and species richness in different habitats. Canadian Journal of Fisheries and Aquatic Sciences, 63, 721-736.

Hinz, H., Tarrant, D., Ridgeway, A., Kaiser, M.J. \& Hiddink, J.G. (2011) Effects of scallop dredging on temperate reef fauna. Marine Ecology Progress Series, 432, 91-102.

Howarth, L.M., Wood, H.L., Turner, A.P. \& Beukers-Stewart, B.D. (2011) Complex habitat boosts scallop recruitment in a fully protected marine reserve. Marine Biology, 158, 17671780 
Jennings, S. \& Kaiser, M. J. (1998) The effects of fishing on marine ecosystems. Advances in Marine Biology, 34, 201-352.

Kaiser, M.J., Clarke, K.R., Hinz, H., Austen, M.C.V., Somerfield, P. J. \& Karakassis, I. (2006) Global analysis of response and recovery of benthic biota to fishing. Marine Ecology Progress Series, 311, 1-14.

Kaiser, M.J., Collie, J.S., Hall, S.J., Jennings, S. \& Poiner, I.R. (2002) Modification of marine habitats by trawling activities: prognosis and solutions. Fish and Fisheries, 3, 114-136.

Kaiser, M.J., Ramsay, K., Richardson, C.A., Spence, F.E. \& Brand, A. R. (2000) Chronic fishing disturbance has changed shelf sea benthic community structure. Journal of Animal Ecology, 69, 494-503.

Lombardi, C., Cocito, S., Occhipinti-Ambrogi, A. and Porter, J.S. (2008) Distribution and morphological variation of colonies of the bryozoan Pentapora fascialis (Bryozoa: Cheilostomata) along the western coast of Italy. Journal of the Marine Biological Association of the UK, 88, 711-717.

MMO. (2014) UK seas fisheries statistics 2014. Marine Management Organisation, London.

Munro, L. \& Munro, C. (2003) Determining the reproductive cycle of Eunicella verrucosa. A report to the England Nature RR Report 07/2004 ETR 12. Reef Research: UK.

Natural England. (2010) Inshore special area of conservation (SAC): Lyme Bay and Torbay, SAC selection assessment document, Version 2.5. Natural England, Sheffield.

Pikesley, S.K., Godley, B.J., Latham, H., Richardson, P.B., Robson, L.M., Solandt, J.L., Trundle, C., Wood, C. and Witt, M.J. (2016) Pink sea fans (Eunicella verrucosa) as indicators of the spatial efficacy of Marine Protected Areas in southwest UK coastal waters. Marine Policy, 64, 38-45. 
Rees, S.E., Attrill, M.J., Austen, M.C., Mangi, S.C., Richards, J.P. \& Rodwell, L.D. (2010) Is there a win-win scenario for marine nature conservation? A case study of Lyme Bay, England. Ocean \& Coastal Management, 53, 135-145.

Roberts, C.M., Hawkins, J.P. \& Gell, F.R. (2005) The role of marine reserves in achieving sustainable fisheries. Philosophical Transactions of the Royal Society B - Biological Sciences, 360, 123-132.

Sciberras, M., Hinz, H., Bennell, J.D., Jenkins, S.R., Hawkins, S.J. \& Kaiser, M.J. (2013) Benthic community response to a scallop dredging closure within a dynamic seabed habitat. Marine Ecology Progress Series, 480, 83-98.

Sheehan, E.V., Cousens, S.L., Nancollas, S.J., Stauss, C., Royle, J. \& Attrill, M.J. (2013a) Drawing lines at the sand: Evidence for functional vs. visual reef boundaries in temperate Marine Protected Areas. Marine Pollution Bulletin, 76, 194-202.

Sheehan, E.V., Stevens, T.F. \& Attrill, M.J. (2010) A quantitative, non-destructive methodology for habitat characterisation and benthic monitoring at offshore renewable energy developments. PLoS One, 5, p.e14461.

Sheehan, E.V., Stevens, T.F., Gall, S.C., Cousens, S.L. \& Attrill, M.J. (2013b). Recovery of a temperate reef assemblage in a Marine Protected Area following the exclusion of towed demersal fishing. PloS one, 8, p.e83883.

Stevens, T.F., Sheehan, E.V., Gall, S.C., Fowell, S.C. \& Attrill, M.J. (2014). Monitoring benthic biodiversity restoration in Lyme Bay marine protected area: Design, sampling and analysis. Marine Policy, 45, 310-317.

Thrush, S.F., Hewitt, J.E., Cummings, V.J. \& Dayton, P.K. (1995) The impact of habitat disturbance by scallop dredging on marine benthic communities: what can be predicted from the results of experiments? Marine Ecology Progress Series 
Williams, A., Schlacher, T.A., Rowden, A.A., Althaus, F., Clark, M.R., Bowden, D.A., Stewart, R., Bax, N.J., Consalvey, M. \& Kloser, R.J. (2010) Seamount megabenthic assemblages fail to recover from trawling impacts. Marine Ecology, 31, 183-199.

Willis, T.J., Millar, R.B., Babcock, R.C. \& Tolimieri, N. (2003) Burdens of evidence and the benefits of marine reserves: putting Descartes before des horse? Environmental conservation, 30, 97-103.

Worm, B., Barbier, E.B., Beaumont, N., Duffy, J.E., Folke, C., Halpern, B.S., Jackson, J.B., Lotze, H.K., Micheli, F., Palumbi, S.R. \& Sala, E. (2006) Impacts of biodiversity loss on ocean ecosystem services. Science, 314, 787-790.

Zuur, A.F., leno, E.N., Walker, N.J., Saveliev, A.A. \& Smith, G.M. (2009) Mixed effects models and extensions in ecology with R. (eds: M. Gail, K. Krickeberg, J.M, Samet, A. Tsiatis \& W. Wong. Spring Science and Business Media, New York, NY. 
Figure 1 Positions of the sample sites (squares) used to investigate temporal changes in epifaunal community composition in Lyme Bay following closure to towed demersal fishing gears over a 10 year period. The same survey design and sample sites used in the baseline survey were adopted (Hinz et al., 2011). The four voluntary reserves implemented in 2006 are outlined in thicker lines and the light blue shaded areas outline the sample sites for the corresponding reserve $(\mathrm{BHG}=$ Beer Home Ground; $\mathrm{LN}=$ Lanes Grounds; $\mathrm{ET}=$ East Tennents; STL = Saw Tooth Ledges). The current MPA boundary, implemented in 2008, is outlined in black. Grey shaded squares represent the sampling sites and colour denotes the four fishing history treatments. East Tennents was not analysed in the present study due to inadequate sample replication. The inset boxes show the UK and wider Lyme Bay with the red rectangle and box indicating the study area respectively.

Figure 2 (A) Mean substrate percentage cover across the four previous fishing treatment (OF=open fished, ONF=open not-fished, $C F=$ closed fished, CNF=closed not-fished) and the two years (2007 and 2016). (B) Mean percentage cover ( \pm SE) of the five substratum categories sampled across video transects during the 2007 (dark grey) and 2016 (light grey) surveys. $\mathrm{S}=$ sand; $\mathrm{G}=$ gravel; $\mathrm{CB}=$ cobbles and boulders; $\mathrm{RR}=$ rocky reef; $\mathrm{BS}=$ brittlestar beds. Only the percentage cover of gravel sediment differed significantly between 2007 and 2016 ( ${ }^{*}$ Mann-Whitney $\left.W=1148, P=0.002\right)$. 
Figure 3 Mean abundance ( \pm 1SE) of the nine epibenthic species sampled to investigate temporal changes following the implementation of the MPA in Lyme Bay in 2008, at previously open fished (OF), open not-fished (ONF), closed fished (CF) and closed notfished (CNF) sites, for the years 2007 (dark grey) and 2016 (light grey).

Figure 4 Recovery plots for the seven sessile species sampled in Lyme Bay, showing the mean carrying capacity $\mathrm{K}$ (black horizontal line) and the fitted relationship for change with time in abundance showing the time to $80 \%$ (t80) and 95\% (t95) recovery relative to $\mathrm{K}$.

Figure 5 Mean individual size $\left(\mathrm{mm}^{2}\right)( \pm 1 \mathrm{SE})$ of six epibenthic species for which we had adequate levels of replication to investigate temporal changes in body-size following the implementation of a MPA in Lyme Bay in 2008, at previously open fished (OF), open notfished (ONF), closed fished (CF) and closed not-fished (CNF) sites, for the years 2007 (dark grey) and 2016 (light grey) Due to insufficient levels of replication it was not possible to make a temporal comparison for Pentapora fascialis and Phallusia mammillata hence only the data for 2016 are shown.

Figure 6 Percentage occurrence of different size classes $(\mathrm{cm})$ of $E$. verrucosa individuals, determined using maximum height $(\mathrm{cm})$ at open fished sites (OF), open not-fished sites (ONF), closed fished sites (CF) and closed not-fished (CNF) during the 2007 and 2016 surveys conducted in Lyme Bay. Samples sizes indicated on figure. 
Table 1: Illustration of the number of years of protection (i.e. recovery timescale) for each of the different fishing treatments. ONF and CNF are both considered to represent the baseline condition and were used to calculate $k$ for each species $(n=4)$. The voluntary closure was implemented in August 2006 which means that the CF treatment was sampled 1 and 10 years post closure. The OF treatment was only protected at the point that Lyme Bay SAC was designated in 2008 , and hence this site was sampled 8 years post closure.

$\begin{array}{ccccc} & \text { OF } & \text { CF } & \text { ONF } & \text { CNF } \\ 2007 & 0 & 1 & >10 & >10 \\ 2016 & 8 & 10 & >10 & >10\end{array}$


Table 2: General linear model outputs on In transformed data for the abundance of individuals $100 \mathrm{~m}^{-2}$ and on square root transformed body-size (surface area $\mathrm{mm}^{2}$ ) of individuals of each species, with fishing history (see Table 1) and year (2007 and 2016) as factors. Multiple pair-wise test are given in Table 3.

Abundance

Alcyonium digitatum

Fishing history

Year

Fishing history * year

Error

Total

\section{Eunicella verucosa}

Fishing history

Year

Fishing history * year

Error

Total
SS MS

3

$6.01 \quad 5.11<0.00$

$\begin{array}{lllll}1 & 54.1 & 54.1 & 46 & <0.001\end{array}$

$\begin{array}{lllll}3 & 13.6 & 4.54 & 3.87 & 0.01\end{array}$

$\begin{array}{lll}110 & 129 & 1.17\end{array}$

$117 \quad 216$

Body-size

$\begin{array}{lccccc}\text { Alcyonium digitatum } & \text { df } & \text { SS } & \text { MS } & \text { F } & \text { P } \\ \text { Fishing history } & 3 & 2576.4 & 858.8 & 3.2 & 0.03 \\ \text { Year } & 1 & 5490.5 & 5490.5 & 20.6 & <0.001 \\ \text { Fishing history * year } & 3 & 651.3 & 217.1 & 0.8 & 0.49 \\ \text { Error } & 67 & 17899 & 267.2 & & \\ \text { Total } & 74 & 25984 & & & \end{array}$

Eunicella verucosa

$\begin{array}{lrrrrr}\text { Fishing history } & 3 & 4274.1 & 1424.7 & 0.97 & 0.42 \\ \text { Year } & 1 & 22384 & 22384 & 15.2 & 0.0001 \\ \text { Fishing history * year } & 3 & 575 & 191.7 & 0.1 & 0.94 \\ \text { Error } & 42 & 61872 & 1473.1 & & \\ \text { Total } & 49 & 90779 & & & \end{array}$


Pecten maximus

Fishing history

Year

Fishing history * year

Error

Total

$117 \quad 72.4$

Pecten maximus

$\begin{array}{lrrrrr}\text { Fishing history } & 3 & 672.1 & 224 & 0.9 & 0.44 \\ \text { Year } & 1 & 10421 & 10421 & 42.2 & <0.001 \\ \text { Fishing history * year } & 3 & 400.5 & 133.5 & 0.5 & 0.66 \\ \text { Error } & 94 & 23224 & 247.1 & & \\ \text { Total } & 101 & 34969 & & & \end{array}$

\section{Aequipecten}

\section{opercularis}

$\begin{array}{lrrrrr}\text { Fishing history } & 3 & 606.4 & 202.1 & 1.78 & 0.17 \\ \text { Year } & 1 & 38.5 & 38.5 & 0.3 & 0.56 \\ \text { Fishing history * year } & 3 & 232.1 & 77.4 & 0.7 & 0.57 \\ \text { Error } & 27 & 3062.9 & 113.4 & & \\ \text { Total } & 34 & 3947.8 & & & \end{array}$

Pentapora fascialis

\section{Pentapora fascialis}

\begin{tabular}{|c|c|c|c|c|c|c|c|c|c|c|}
\hline Fishing history & 3 & 27.7 & 9.25 & 8.52 & $<0.001$ & Fishing history & 3 & 1851 & 617 & 0.9 \\
\hline Year & 1 & 2.36 & 2.36 & 2.18 & 0.14 & Error & 24 & 15095 & 629 & \\
\hline
\end{tabular}




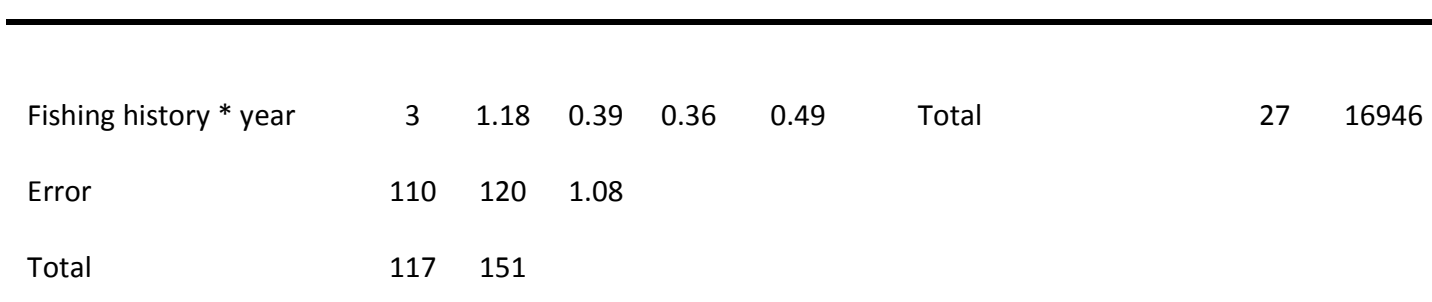

Phallusia mammillata

Fishing history

Year

Fishing history * year

Error

Total

Axinella dissimilis

Fishing history

Year

Fishing history * year

Error

Total

Cancer pagurus

Fishing history
3

$\begin{array}{lllll}1 & 30.6 & 30.6 & 30.1<0.001\end{array}$

$\begin{array}{lllll}3 & 5.01 & 1.67 & 1.64 & 0.18\end{array}$

$\begin{array}{lll}110 & 112 & 1.02\end{array}$

$117 \quad 166$

$\begin{array}{lllll}3 & 8.49 & 2.83 & 10 & <0.001 \\ 1 & 0.01 & 0.01 & 0.04 & 0.84 \\ 3 & 0.16 & 0.05 & 0.19 & 0.9 \\ 10 & 31.1 & 0.28 & & \\ 117 & 39.8 & & \end{array}$

Phallusia mammillata

3473

157

0.9

0.45

Error

$30 \quad 5212$

174

$33 \quad 5686$

Total 


\begin{tabular}{lccccc}
\hline & 1 & 0.02 & 0.02 & 0.35 & 0.55 \\
Year & 3 & 0.12 & 0.04 & 0.54 & 0.66 \\
Fishing history * year & 110 & 8.52 & 0.07 & & \\
Error & 117 & 8.81 & & & \\
Total & & & & & \\
& & & & & \\
Maja squinado & & & & & \\
Fishing history & 3 & 0.94 & 0.31 & 4.49 & 0.01 \\
Year & 1 & 0.71 & 0.71 & 10.1 & $<0.001$ \\
Fishing history * year & 3 & 0.14 & 0.05 & 0.71 & 0.55 \\
Error & 110 & 7.71 & 0.07 & & \\
Total & 117 & 9.54 & & &
\end{tabular}


Table 3: Coefficient $(r)$ for the logistic recovery curves, probability $(p)$ and the mean carrying capacity $(K)$ for each of the species for which recovery curves were fitted, plus the time (year) to recover to $80 \%$ (t80) and $95 \%$ (t95) of $\mathrm{K}$.

$\begin{array}{rrrrrr} & \mathrm{r} & \mathrm{p} & \mathrm{t} 80 & \mathrm{t} 95 & \mathrm{~K} \text { mean } \\ \text { Alcyonium digitatum } & 2.21 & 0.51 & 1.8 & 2.5 & 28.03 \\ \text { Axinella dissimilis } & 0.09 & 0.03 & 34.6 & 51.1 & 1.37 \\ \text { Eunicella verrucosa } & 0.14 & 0.005 & 18.7 & 30.2 & 27.91 \\ \text { Pentapora fascialis } & 0.16 & 0.001 & 16.6 & 26.1 & 7.81 \\ \text { Phallusia mamillata } & 0.2 & 0.001 & 16.9 & 24.7 & 10.25 \\ \text { Aequipecten opercularis } & 0.05 & 0.001 & \mathrm{NaN} & \mathrm{NaN} & 12.7 \\ \text { Pecten maximus } & 3.54 & 0.31 & 0.3 & 0.7 & 12.71\end{array}$


Figure 1

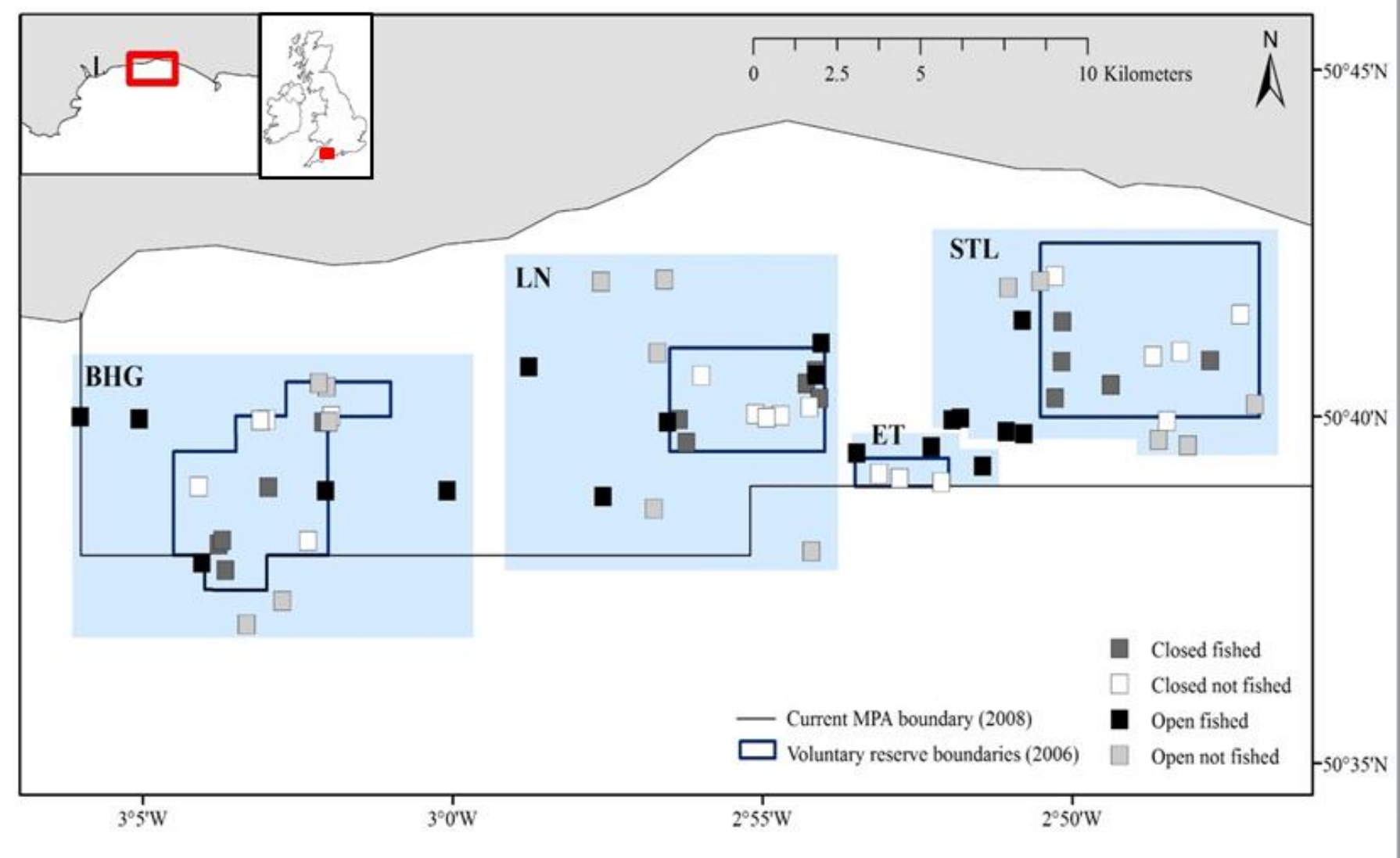


Figure 2

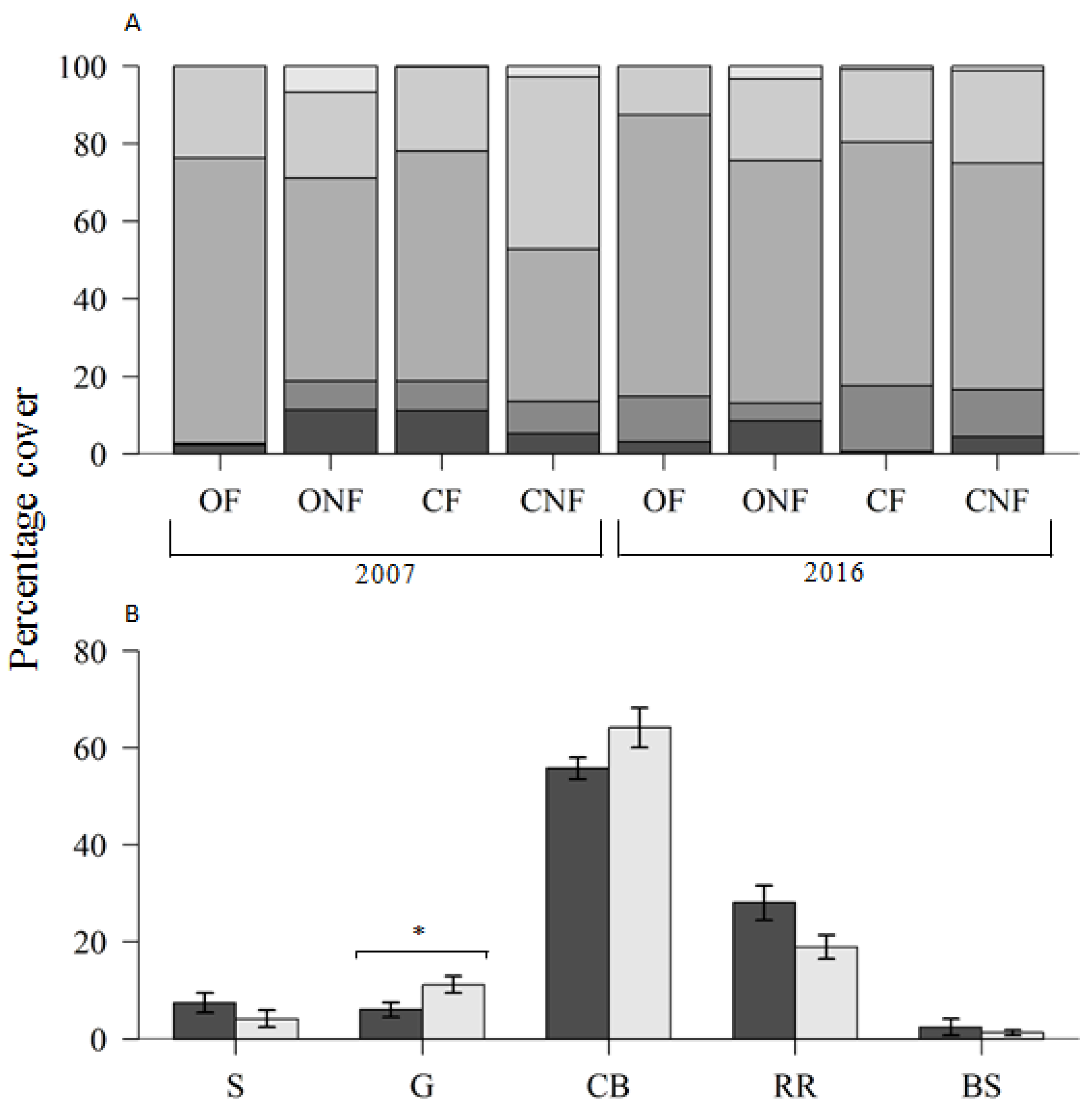


Figure 3
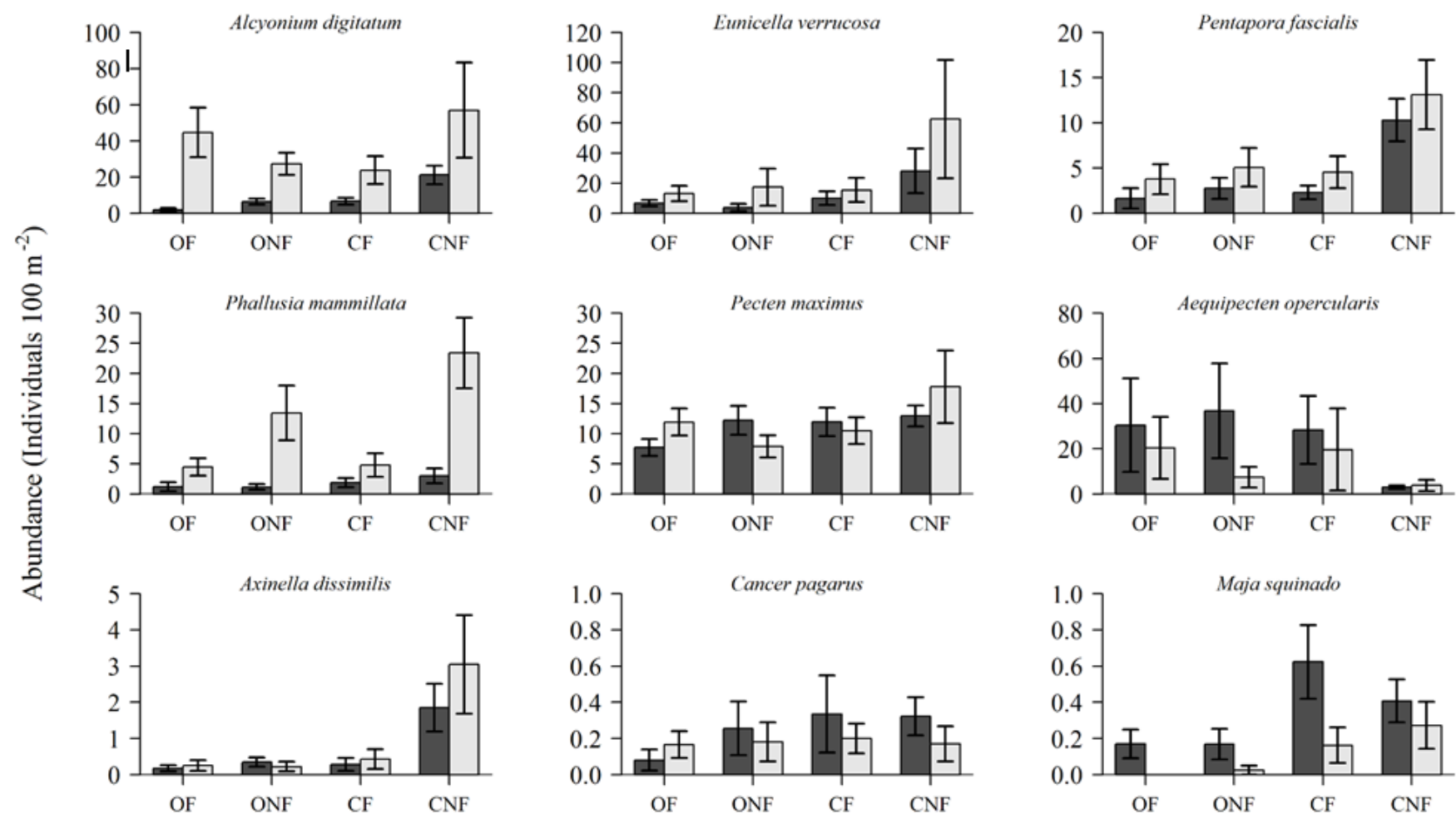

Treatment 
Figure 4
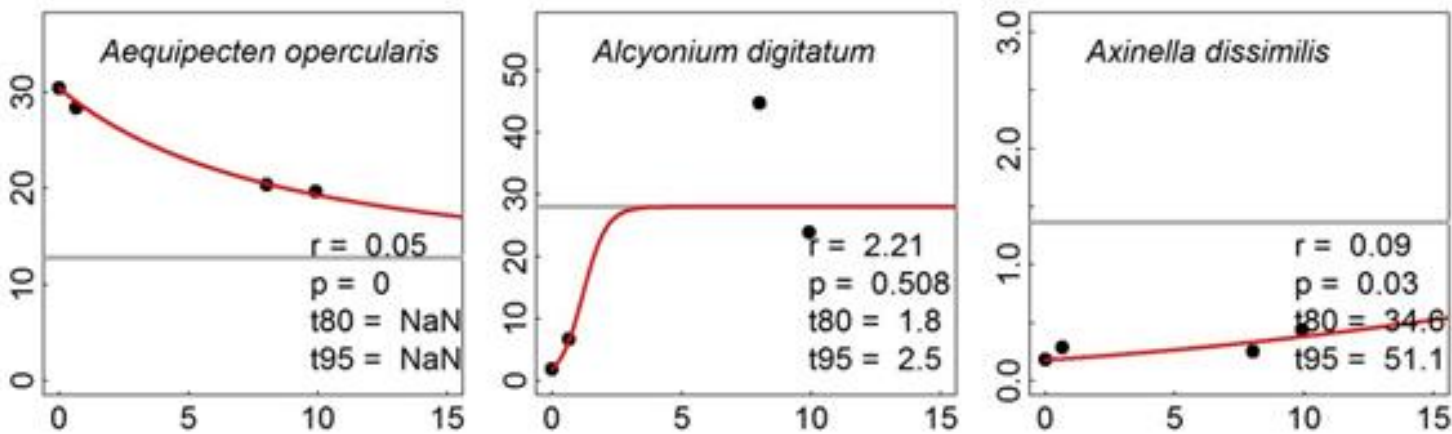

尚
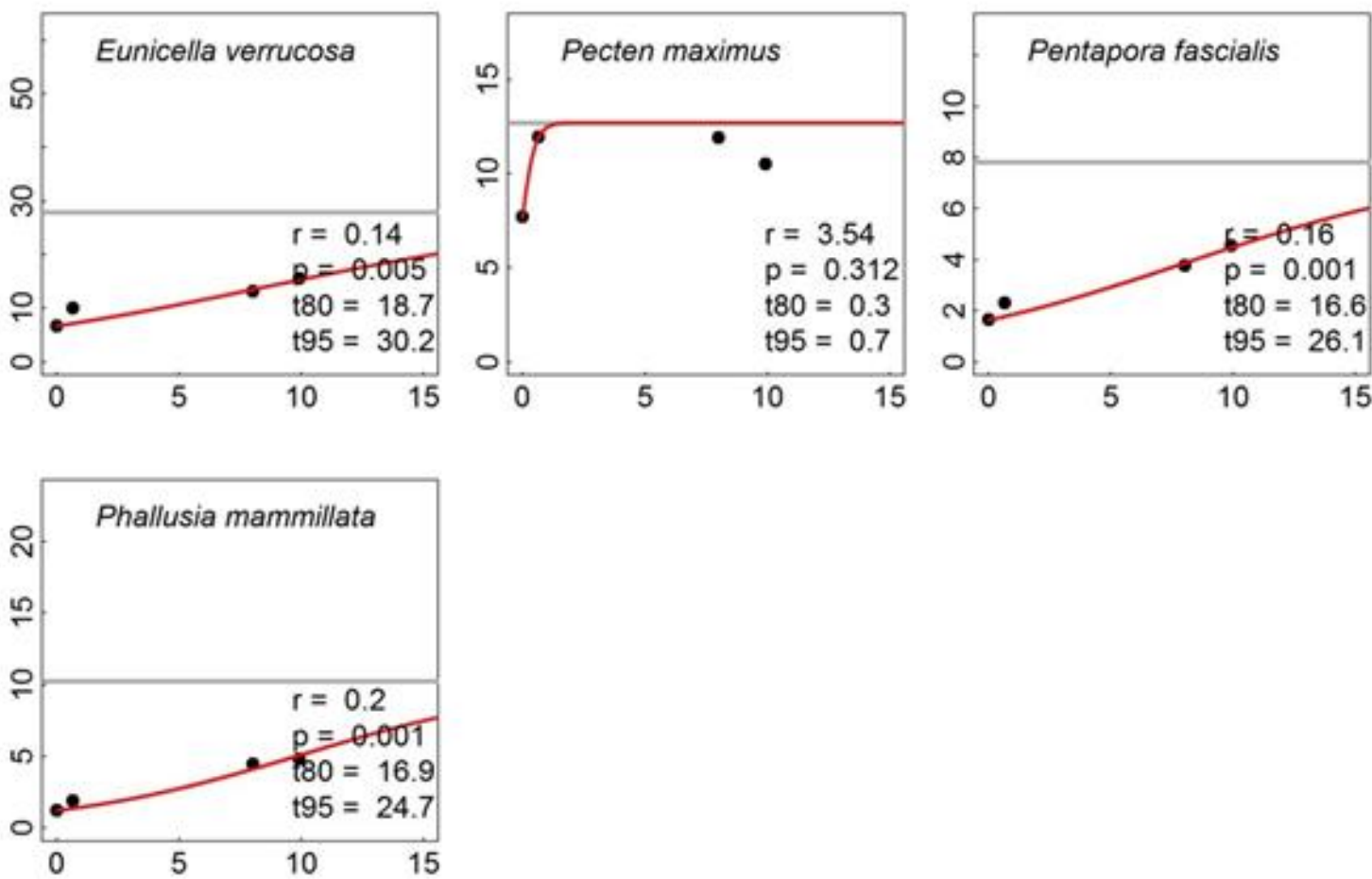

Years to recovery 
Figure 5
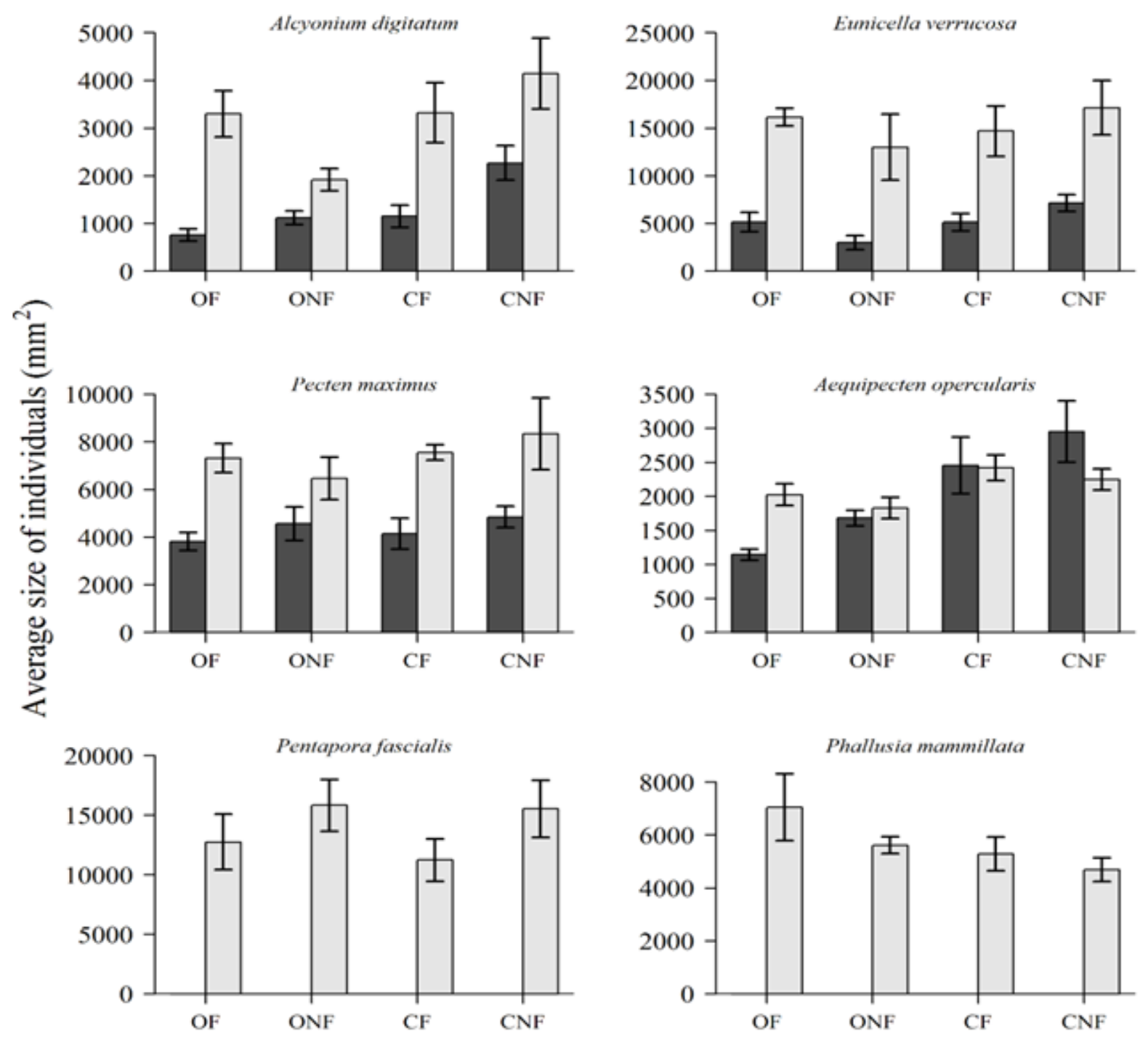

Treatment 
Figure 6
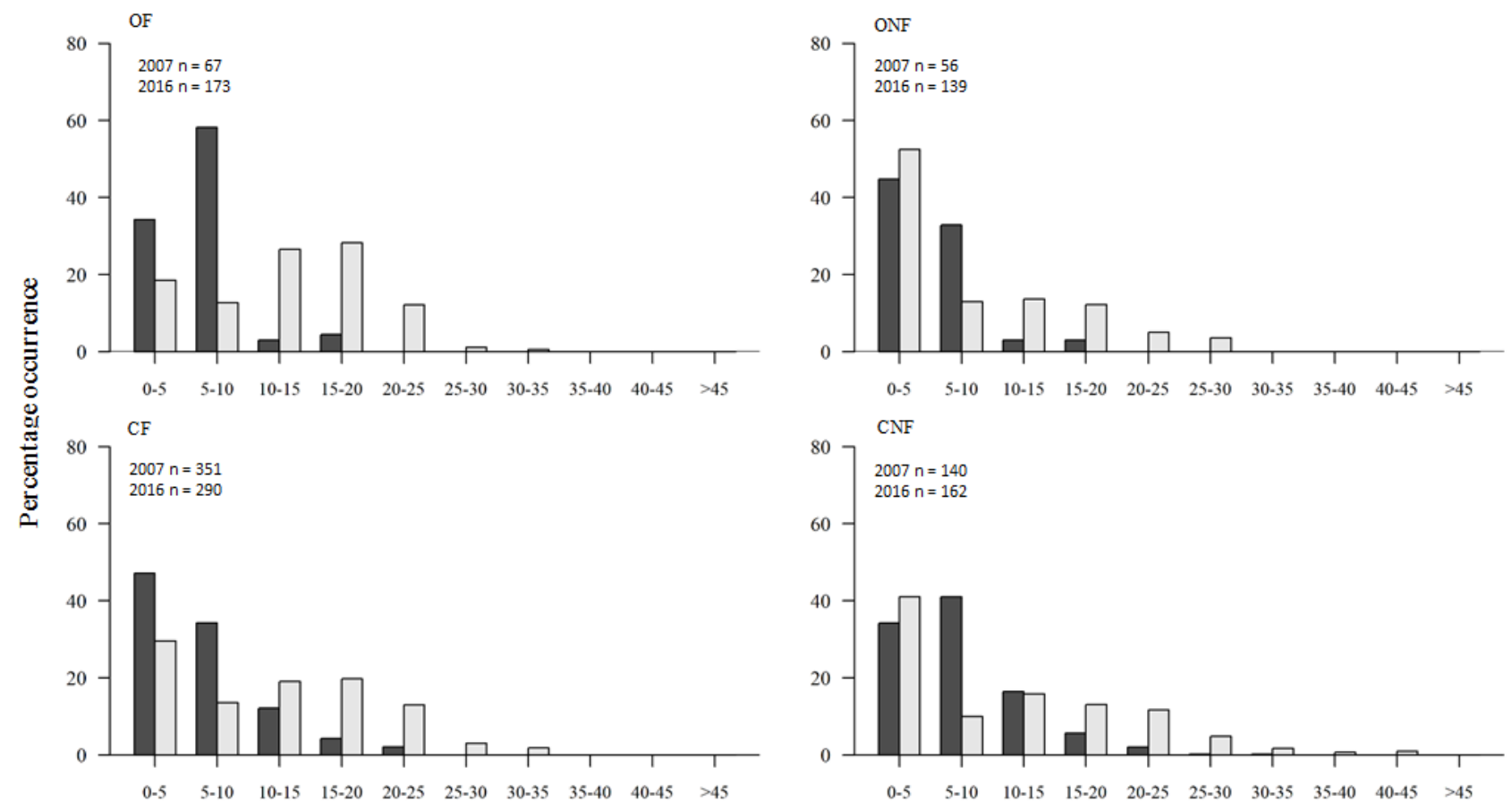

Size class $(\mathrm{cm})$ 